\title{
EVALUATION OF SUSCEPTIBILITY TO TEMPER BRITTLENESS OF HEAT-RESISTANT STEELS USING HIGH-TEMPERATURE TESTING
}

\author{
V.Yu. SKULSKY ${ }^{1}$, V.V. ZHUKOV', M.A. NIMKO' , S.I. MORAVETSKY ${ }^{1}$ and L.D. MISHCHENKO \\ ${ }^{1}$ E.O. Paton Electric Welding Institute, NASU \\ 11 Kazimir Malevich Str., 03680, Kiev, Ukraine. E-mail: office@paton.kiev.ua \\ ${ }^{2}$ Company «Turboatom» \\ 199 Moskovsky Ave., 61037, Kharkov, Ukraine. E-mail: office@turboatom.com.ua
}

\begin{abstract}
Main point of problem of crack formation in tempering is defined. It is shown that low metal ductility during plastic deformation, promoted by stress relaxation is a condition for nucleation of such cracks. Important brittleness factor under these conditions is temporarily developing secondary hardening, related with nucleation and precipitation of secondary phases in matrix. Since alloys with different level of alloying demonstrate different behavior during tempering, then evaluation of their possible tendency to temper brittleness is of interest in each specific case. A procedure is described for high-temperature tensile testing, which allows evaluating ductile properties of metal under different tempering conditions. Susceptibility to temper brittleness was evaluated using a criterion of value of relative reduction in area $\psi \leq 25 \%$. Studied was a nature of ductility change in complexly-alloyed heat-resistant steels under different tempering modes resulting in secondary hardening condition and after hardening stage. It is shown that steels in a period of steel hardening development have low ductility with typical for such a state intergranular fracture. Determined are critical tempering modes, under which a high ductility state is achieved, based on which absence of susceptibility to tempering cracks can be predetermined. 9 Ref., 1 Table, 8 Figures.
\end{abstract}

K e y w or d s : hardening steels, tempering, cracks, secondary hardening, tempering ductility, high ductility condition

Crack formation in process of tempering or re-heating in heat-hardenable steels and their welded joints is a result of combination of three factors, i.e. structural (caused by secondary hardening), brittleness (related with precipitation along grain boundary of secondary phases and segregation of additives), and force (in form of stresses promoted by formation of hardening structures, metal shrinkage or applied external loading).

Force factor, which is based on energy of elastic distortions accumulated in a crystal system, promotes development of relaxation plastic deformations in heating. Deformation acquires a local nature, namely concentrates along grain boundaries or in area of more compliant (soft) structural constituents, under conditions of reduced ductility, caused by secondary hardening. Small ductility resource of such areas and additional segregation of additives increase the possibility of nucleation of such mircodefects and formation of cracks.

The cracks having small size and being located inside the metal can remain undetected, if nondestructive testing is carried out before final heat treatment. Therefore, it is important to determine the possibility and conditions for formation of such cracks before production of commercial products in order to apply preventive measures.
Different method are used in research practice for checking steel and their welded joints susceptibility to brittleness and formation of cracks in tempering. Specimens of small size from homogeneous metal as well as cut out from the welded joints can be used. In series of cases special fitting or equipment are necessary. More convenient and less time-consuming are the experimental methods allowing eliminating operations related with welding from preparation cycle, and using simple for production specimens of small size. Such a method can be high-temperature tensile testing [1-3]. At that, value of relative reduction in area $\psi=25 \%$ [3] can be used as brittleness criterion, i.e. metal is susceptible to tempering cracks at lower values. In earlier works [4] Vinkier and Pense determined $\psi=20 \%$ as a threshold value.

The aim of present work lied in investigation of effect of tempering modes of preliminary hardened energy-machine building steels on temper brittleness using the method of high-temperature tensile tests.

Tests were carried out on Gleeble 380 unit. Cylindrical specimens of $10 \mathrm{~mm}$ diameter with parts threaded at the ends for their fixing in loading jaws were used. Heating on set mode was performed with the help of current passed through the specimen from connected to it copper grips. In order to guarantee 
fracture in operating part (between the grips), the specimens include cavity of smaller diameter $(6 \mathrm{~mm})$ in the center.

Cast, forged and hot-worked heat-resistant steels P3 (15Kh2M2FBS), EI415 (20Kh3VMFA) and P91 (X10CrMoVNb91) (10Kh9MFB type) were used as pilot materials. Time-temperature diagrams, limiting secondary hardening areas, were plotted on results of hardness measurement after different tempering modes (different holding at various temperatures) of preliminary quenched specimens. Weld metal specimens of similar alloying system were used in these experiments for steel P91; received experimental hardening diagrams served a marker for choosing the conditions of further tensile tests using specimens from hot-worked pipe steel.

The following approach is used for tensile tests at selected temperatures. It is known fact that the tempering cracks are formed as a result of slowly developing plastic deformation - relaxation creep (based on data of work [2], deformation rate (relative elongation) makes $10^{-4}-10^{-5} \% / \mathrm{h}$ ). Under such conditions deformation initiates precipitation of carbide phases, promoting brittleness of grain boundaries [5], and, hypothetically, displacement of additive atoms together with moving dislocations to the boundaries becomes possible. In simple static tensile tests the deformation rates are higher and no signs of brittleness can be observed.

As was shown by Dix and Savage using the example of nickel alloy [6], high-temperature brittleness appeared at small deformation rates; in tension with more than $25 \mathrm{~mm} / \mathrm{min}$ rate the brittleness effect became weaker and metal had increased ductility. Sufficiently low specimen deformation rate was also created for tests carried out in present work, namely grips movement speed made $0.04 \mathrm{~mm} / \mathrm{min}$.

The experiment had two heating cycles (Figure 1). The first cycle provided for specimen heating to $T_{\max }=1250^{\circ} \mathrm{C}$ for $5 \mathrm{~s}$, holding during $15 \mathrm{~s}$ and further accelerated cooling to room temperature with $w_{6 / 5}=$ $=40{ }^{\circ} \mathrm{C} / \mathrm{s}$ in $600-500{ }^{\circ} \mathrm{C}$ interval. This stage was used for reconstruction of the condition of welding heating and HAZ quenching. The second cycle was spent for slow $\left(2{ }^{\circ} \mathrm{C} / \mathrm{s}\right)$ heating up to necessary heat treatment temperature, holding at set temperature for preliminary selected time, and then specimen was deformed (at the same temperature). Temperature and holding time were set based on time-temperature boundaries of the secondary hardening areas. In some cases specimens after heat treatment, corresponding to achievement of hardening state and, respectively, low ductility were tested. In other cases they were examined after treatment mode providing coming

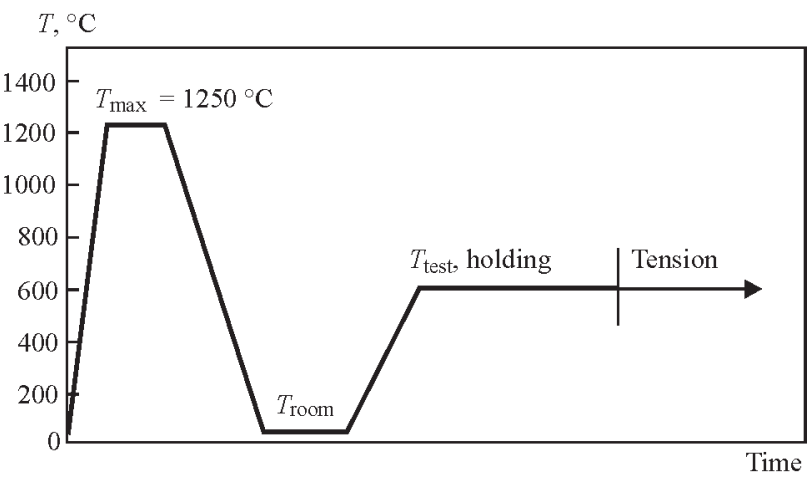

Figure 1. Temperature cycles of experiments

out from the hardening area, when metal should become more ductile. More «rigid» in comparison with work [4] criterion $\psi=25 \%$ was taken. Heat mode of treatment in the experiments was evaluated with the help of Larson-Miller parameter $P_{\mathrm{LM}}$ which simultaneously considers absolute temperature $T(\mathrm{~K})$ and time of heat effect on metal $\tau(\mathrm{h})$ namely $P_{\mathrm{LM}}=$ $=T(20+\lg (\tau))$.

Figure 2 demonstrates preliminary carried investigations on susceptibility to secondary hardening. The registered hardening areas have different time-temperature limits. The general point is their reduction and shifting to small holding durations with temperature increase, that is caused by amplification of thermal activation of atoms diffusion in the crystal system, quick nucleation, precipitation and coarsening of carbide and carbide-nitride phases
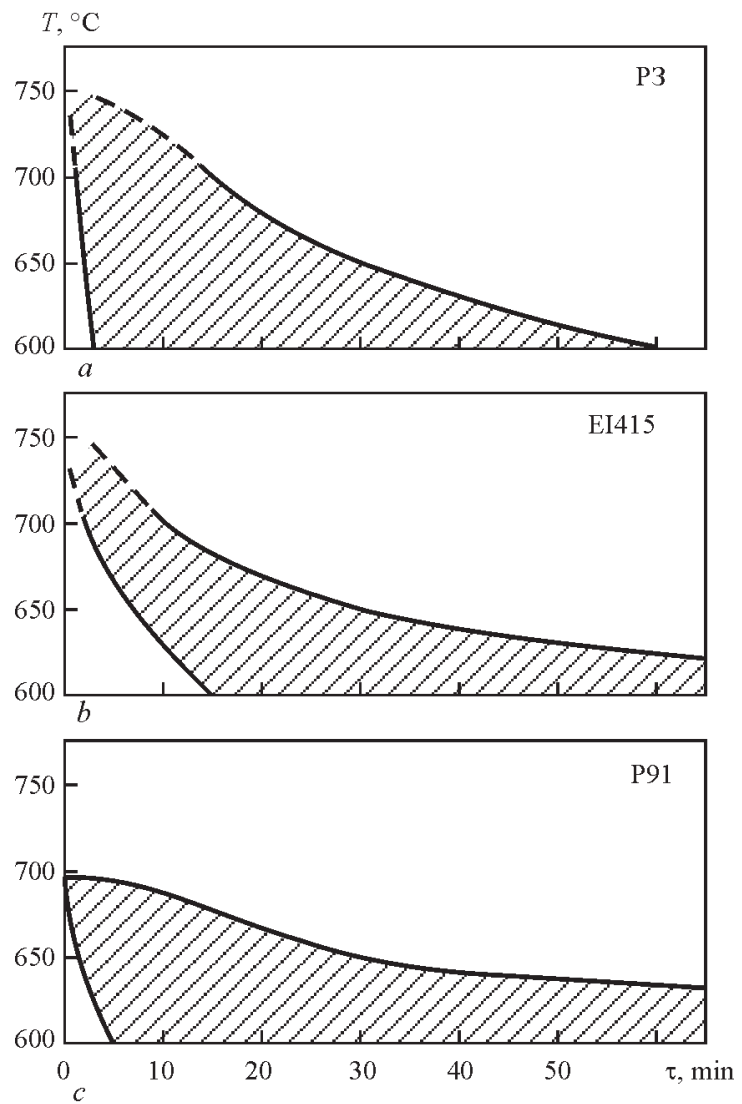

Figure 2. Diagrams of secondary hardening for steels used $(a-c)$ 


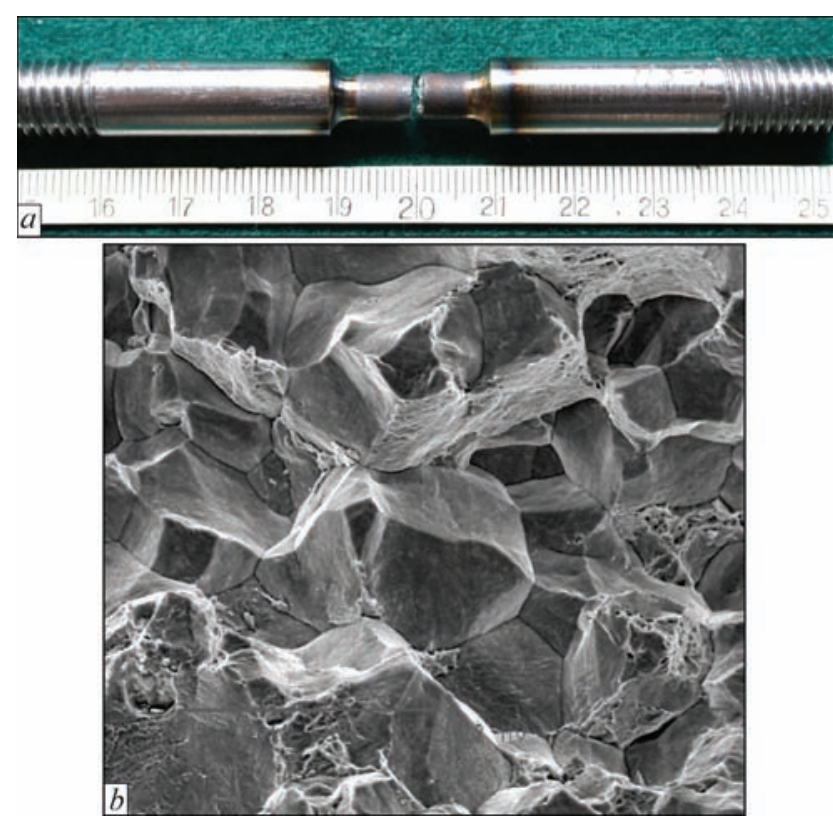

Figure 3. Nature of specimen fracture under conditions of development of secondary hardening in metal: $a$ - specimen after testing; $b$ - fracture surface $(\times 600)$

(depending on steel alloying system), and as a result, quick transfer to solid solution softening stage.

The Table shows the modes of specimen heat treatment. Positions I and II correspond to tests in hardening state and out of hardening areas.

The results showed that metal is susceptible to brittle fracture under secondary hardening condition. Reduction in area values received under these conditions lied at sufficiently low level in $\psi=1.7-$ $6.0 \%$ range. Specimens fractured virtually without thinning with typical for such a condition mainly intergrainular facture* (Figure 3).

As shown in Figure 4, low ductility is preserved in some intervals of time-temperature parameters $P_{\mathrm{LM}}$ in the ranges of areas of secondary hardening as well as out of its boundaries. Boundary values $P_{\mathrm{LM}}^{\mathrm{B}}$ (inclined dashed lines), calculated on hardening diagrams, make (17.5-18.9) $10^{3}$ and $(17.7-18.7) \cdot 10^{3}$ for $\mathrm{P} 3$ and EI415 steels, respectively, in $700-600{ }^{\circ} \mathrm{C}$ range, and $(15.8-16.2) \cdot 10^{3}$ for steel $\mathrm{P} 91$ in $550-500{ }^{\circ} \mathrm{C}$ range.

In contrast to steels EI415 and P91, in which $\psi$ values start rising out of the hardening area, ductility of steel P3 remains very small in some interval of modes exceeding the maximum tempering. Thus, relative reduction in area of steel P3 specimens remained at initially low level in testing at $700{ }^{\circ} \mathrm{C}$ after holding up to $40 \mathrm{~min}$, which is obviously higher than evaluated experimental time for hardening stage finishing (around $15 \mathrm{~min}$ ). Probably, in this
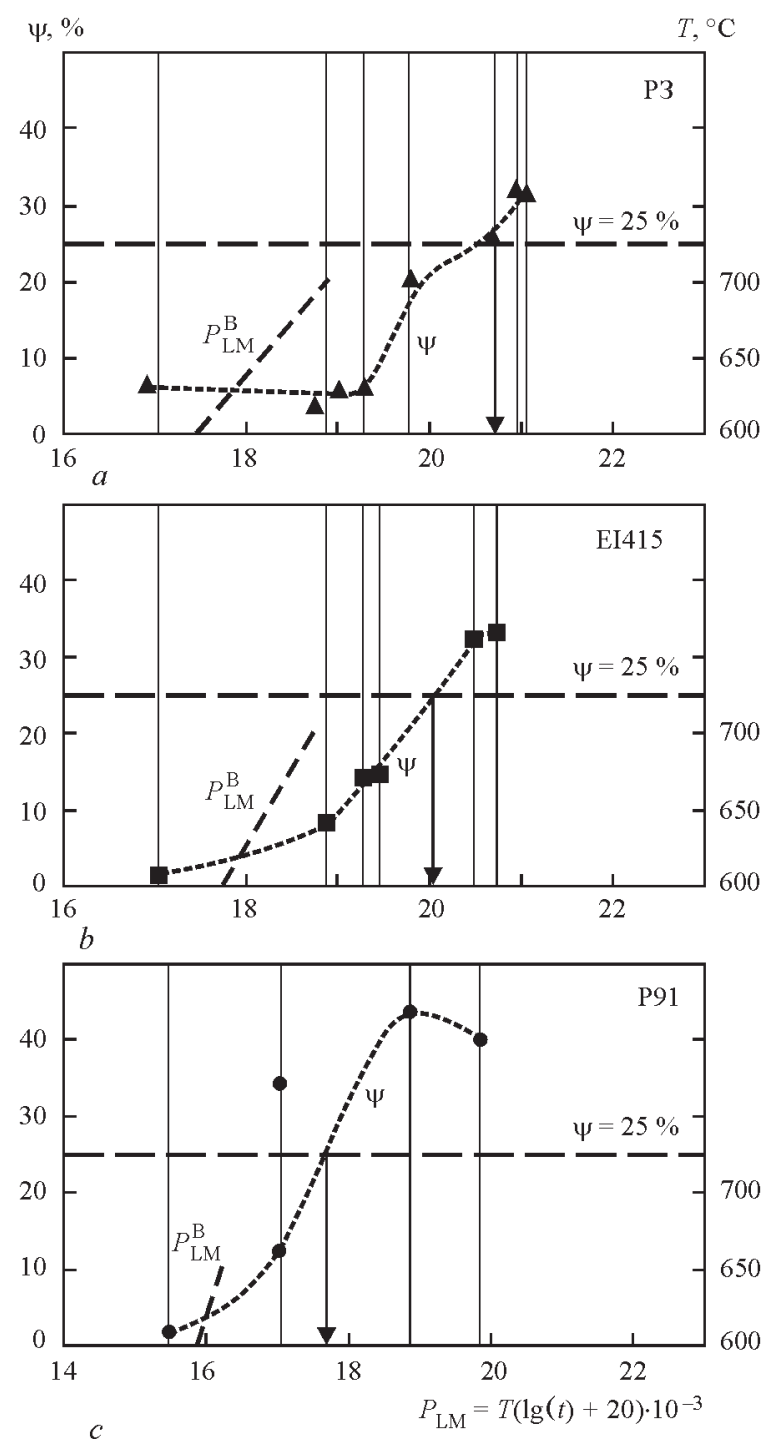

Figure 4. Change of relative reduction in area $\psi$ depending on parameter $P_{\mathrm{LM}}$, and relationship of time-temperature boundaries of hardening $P_{\text {LM }}^{\mathrm{B}}$ with tempering temperature $T$ for steels used $(a-c)$

case an additional effect of process of activation of precipitation of plastic deformation carbide phases on hardening development can appear [5]. It could result in a shift of boundaries of the hardening area to the side of longer holding time relatively to their position determined based on hardness measurement. Also, there is a possibility of effect of another type carbide precipitations [5, 7-9] on additional hardening and limitation of plasticity improvement at elevated temperature (and deformation).

In whole, studied steels demonstrate increase of high-temperature ductility (see Figure 4) after hardening stage is finished. Moreover, in steel P91** this transfer takes place more abrupt at lower values and in narrower range of $P_{\mathrm{LM}}$ parameter. Under such

\footnotetext{
${ }^{*}$ Metallographic examinations were carried out with the participation of T.A. Alekseenko.

${ }^{* *}$ Testing at $600{ }^{\circ} \mathrm{C} / 20 \mathrm{~min}$ showed larger spread of $\psi$ values. Lower value was considered in carried analysis as the possible worth variant of ductility.
} 
Modes of specimen heat treatment

\begin{tabular}{|c|c|c|c|c|}
\hline Steel & Group of testing & Sample number & Quenching at $T,{ }^{\circ} \mathrm{C} / \tau, \min$ & $P_{\mathrm{LM}} \cdot 10^{-3}$ \\
\hline \multirow{9}{*}{ P3 (15Kh2M2FBS) } & \multirow{3}{*}{ I } & 1 & $600 / 20$ & 17.04 \\
\hline & & 2 & $700 / 15$ & 18.87 \\
\hline & & 3 & $700 / 15$ & 18.87 \\
\hline & \multirow{6}{*}{ II } & 4 & $700 / 40$ & 19.29 \\
\hline & & 5 & $740 / 20$ & 19.78 \\
\hline & & 6 & $760 / 60$ & 20.66 \\
\hline & & 7 & $750 / 100$ & 20.69 \\
\hline & & 8 & $750 / 180$ & 20.95 \\
\hline & & 9 & $780 / 60$ & 21.06 \\
\hline \multirow{6}{*}{ EI415 (20Kh3MVF) } & \multirow{2}{*}{ I } & 1 & $600 / 20$ & 17.04 \\
\hline & & 2 & $700 / 15$ & 18.87 \\
\hline & \multirow{4}{*}{ II } & 3 & $700 / 40$ & 19.29 \\
\hline & & 4 & $700 / 60$ & 19.46 \\
\hline & & 5 & $740 / 100$ & 20.48 \\
\hline & & 6 & $740 / 180$ & 20.74 \\
\hline \multirow{5}{*}{ P91 (X10CrMoVNb9-1) } & $\mathrm{I}$ & 1 & $520 / 20$ & 15.48 \\
\hline & \multirow{4}{*}{ II } & 2 & $600 / 20$ & 17.04 \\
\hline & & 3 & $600 / 20$ & 17.04 \\
\hline & & 4 & $700 / 15$ & 18.87 \\
\hline & & 5 & $760 / 10$ & 19.86 \\
\hline
\end{tabular}

conditions $\psi$ increased to higher level (not lower than $40 \%$ at $\left.P_{\mathrm{LM}} \approx(18.9-19.9) \cdot 10^{3}\right)$ than in steels $\mathrm{P} 3$ and EI415. The latter were more «inert» in process of transfer from high to low ductility. The maximum $\psi$ values achieved lower level also at larger values of $P_{\text {LM }}$ parameter, i.e. $32-33 \%$ at $P_{\text {LM }} \approx 30 \cdot 10^{3}$ in steel $\mathrm{P} 3$, and $33-34 \%$ at $P_{\mathrm{LM}}=(25-27) \cdot 10^{3}$ in steel EI415. The following critical values of tempering parameter were determined using received experimental curves. They allow reaching criterial relative reduction in area, namely $25 \%$ at $\psi=20.7 \cdot 10^{3}$ for cast steel P3, $20 \cdot 10^{3}$ for forged steel EI415, and $17.6 \cdot 10^{3}$ for hotworked pipe steel P91.

Energy characteristic of fracture resistance can be a work of crack propagation, which is nucleated in the specimen after reaching specific loading (stress). A measure of work of crack propagation $A_{\mathrm{w}}$ is an area under the part of fracture diagram after crack appearance. However, determination of such a characteristic on tension diagram is not very accurate, since it is difficult to determine the stress, at which

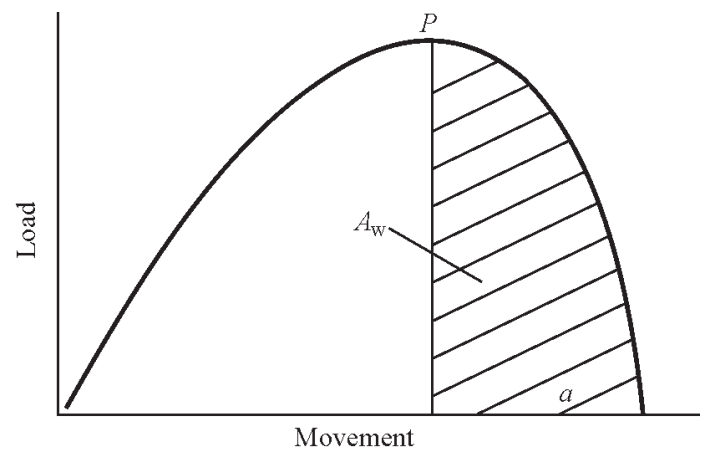

Figure 5. Scheme of tension diagram and calculated area corresponding to work of fracture propagation $A_{\mathrm{w}}$ the crack is nucleated. For this reason, the evaluation of metal resistance to crack propagation carried out in the work shall be considered approximate, however,
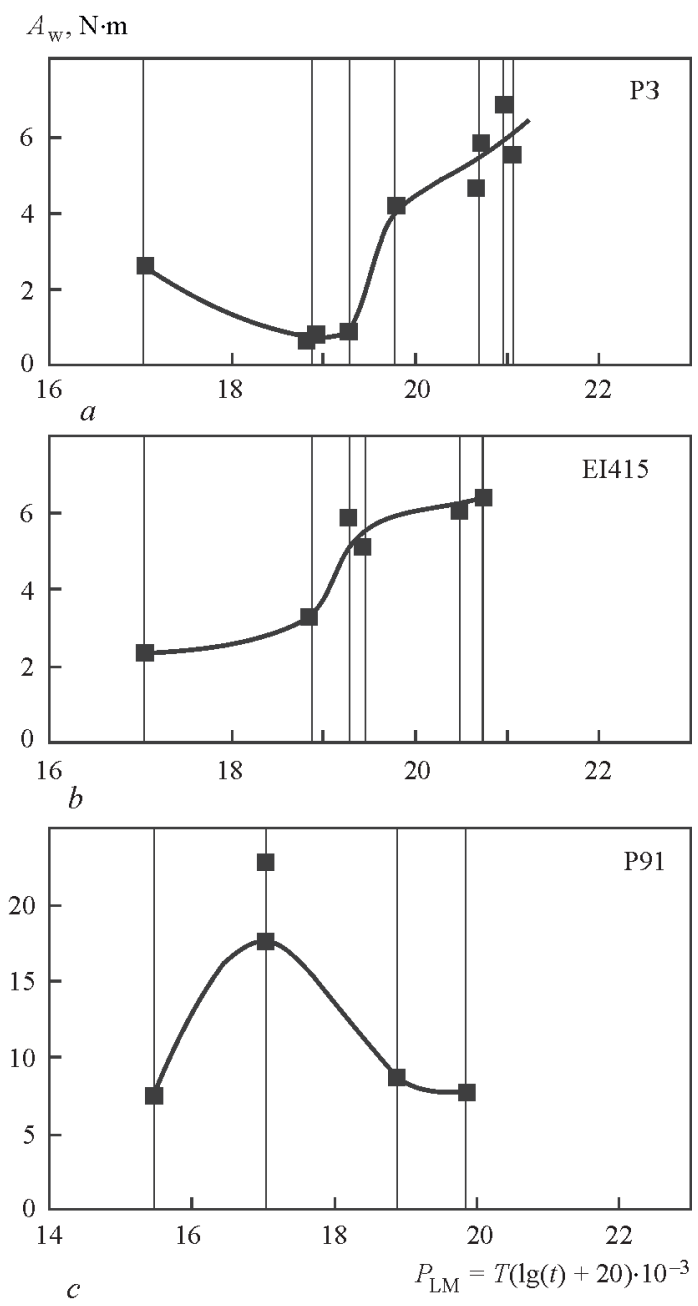

Figure 6. Computation values of fracture work $A_{\mathrm{w}}$ for steels used $(a-c)$ 


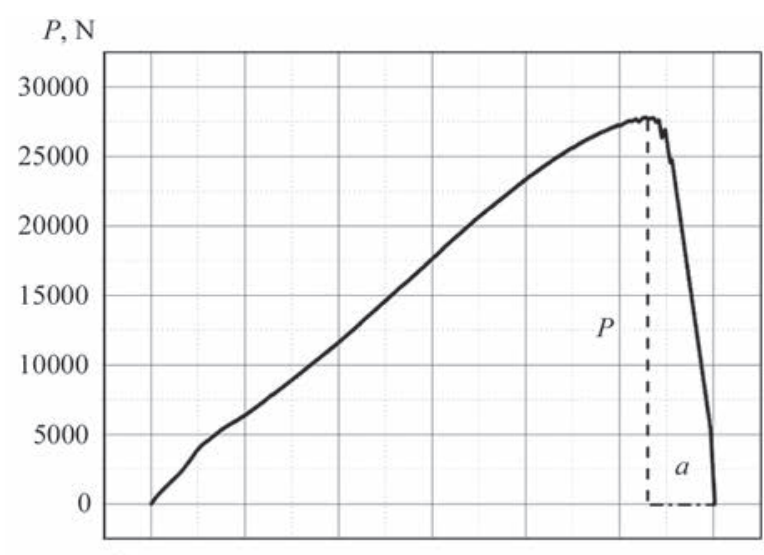

$a$

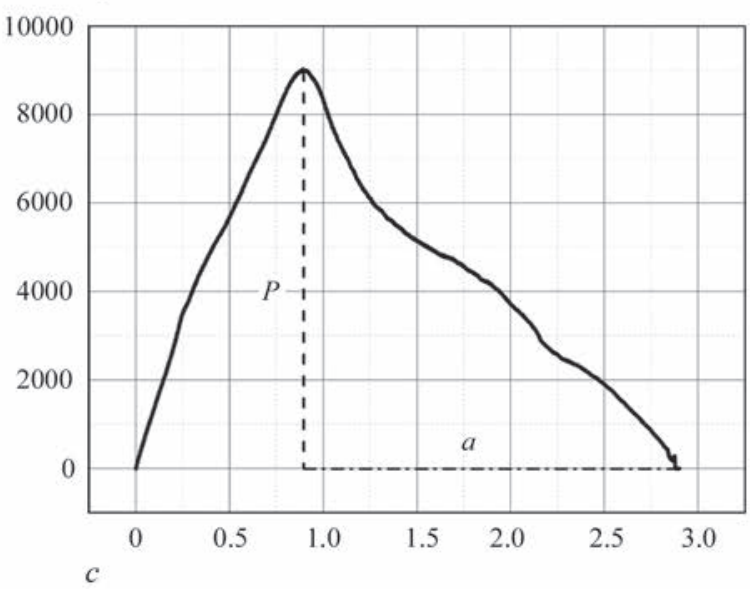

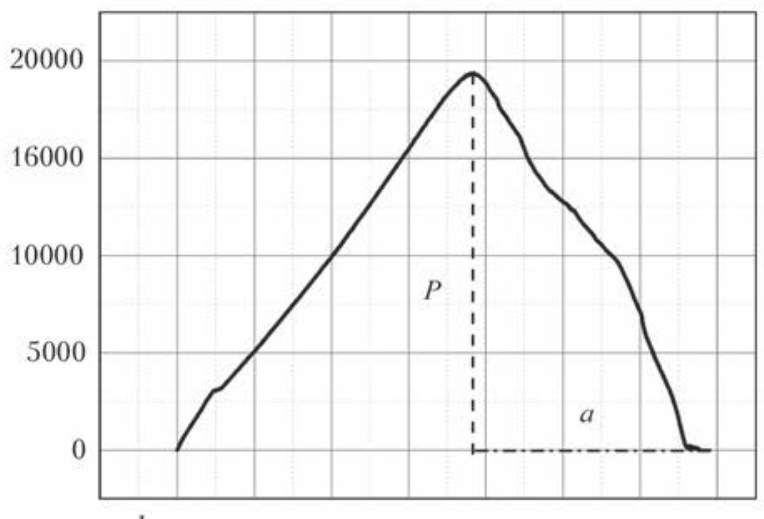

b

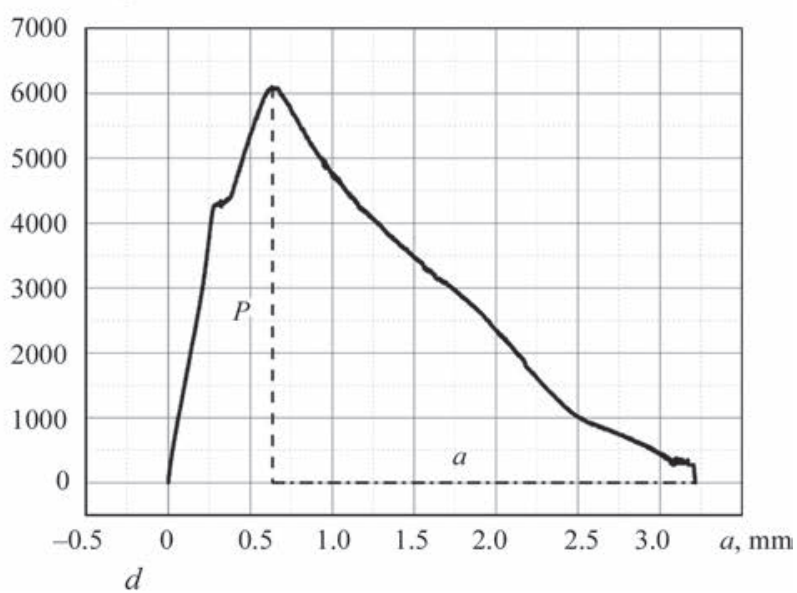

Figure 7. Diagrams of tension of steel P91 specimens for $P_{\mathrm{LM}}=15.48 \cdot 10^{3}(a), 17.04 \cdot 10^{3}(b), 18.87 \cdot 10^{3}(c)$ and $19.86 \cdot 10^{3}(d)$

it illustrates the relationship with determined above indices of ductility. In this case the work of crack propagation was evaluated using an area under descending branch of the diagram after reaching maximum loading $P$ in areas corresponding to the movement $a$ of machine grips (Figure 5). At that, it was assumed that specimens have already had fracture centers at this stage. Corresponding calculations of the areas (Figure 6) on diagrams of tension received in tests were carried out by integration method using Origin 7.5 program (Origin Lab Corp., USA) .

Comparing indicated results and data in Figure 4 it can be noted that steels P3 and EI415 have some disagreement in change of fracture work and relative reduction in area at rise of $P_{\mathrm{LM}}$ tempering parameter. Nature of change of these characteristics is different in the case of steel P91. The reason of observed differences lies in relationship of values of maximum (fracture) force $P$ and registered movement $a$ at fracture stage (Figure 7). Thus, in the case of initial testing with $P_{\mathrm{LM}}=15.48 \cdot 10^{3}$ the metal had high strength and sufficiently small movement $a$, corresponding to brittle fracture susceptibility. Computation fracture work $A_{\mathrm{w}}$ made $7.5 \mathrm{~N} \cdot \mathrm{m}$. Maximum $A_{\mathrm{w}}$ value was received in testing at $P_{\mathrm{LM}}=17.04 \cdot 10^{3}$. Movement in fracture increased in this state, and force was kept at high level. In the last two tests, reduction of fracture force took place regardless the rise of movement values, that resulted in decrease of resultant $A_{\mathrm{w}}$ values. It can be assumed that such steel behavior is determined by the peculiarities of structural changes developing in tempering and high-temperature deformation.

Constituent of fracture work, namely movement of machine grips $a$ at fracture stage (Figure 8), is used as a characteristic of brittle fracture resistance for larger level of agreement with nature of $\psi$ change, instead of the fracture work. It follows from the latter dependencies that high resistance of studied steels to crack formation due to re-heating is achieved at their such condition, under which movement during tensile testing in processes of tempering exceeds $a=1.2-$ $1.5 \mathrm{~mm}(1.5,1.2$ and $1.5 \mathrm{~mm}$ for steels P3, EI415 and P91, respectively, determined for the conditions indicated by arrows of critical values of parameter $P_{\mathrm{LM}}$ ).

In the conclusion it should be noted that secondary hardening can periodically appear at different stages of tempering. Wavy changes of hardness (increase and decrease) at longer holdings were registered after the first (considered above) stage in given investigations of hardening susceptibility. However, such temporary rises of hardness values were insignificant against a background of already achieved total softening of solid solution. This work paid specific attention to the first stage of hardening found in the process of relatively 
short holdings (up to $\sim 3 \mathrm{~h}$ ). An interest to this period is caused by the fact that stress relaxation is developed, in particular at the beginning of tempering, that under conditions of ductility degradation due to hardening results in possibility of microdefect formation.

\section{Conclusions}

1. Time-temperature areas of development of secondary hardening were determined under conditions of high-temperature tempering of steels 15Kh2M2FBS, 20Kh3VMFA and X10CrMoVNb9-1, which were preliminary quenched using simulation welding thermal cycle. The external boundaries of hardening areas correspond to the following LarsonMiller parameter: $P_{\mathrm{LM}}=(17.5-18.9) \cdot 10^{3}$ and $(17.7-$ 18.7) $\cdot 10^{3}$ for steel $\mathrm{P} 3$ and $\mathrm{E} 415$ in $700-600{ }^{\circ} \mathrm{C}$ range, and $P_{\mathrm{LM}}=(15.8-16.2) \cdot 10^{3}$ for steel $\mathrm{P} 91$ in $550-500^{\circ} \mathrm{C}$ temperature range. Nature of change of ductility depending on tempering modes and condition of studied steels can be illustrated with the help of method of high-temperature tensile tests. It is shown that steel has low ductility and susceptible to brittle intergranular fracture under conditions of secondary hardening.

2. Value of relative reduction in area $\psi \leq 25 \%$ was used as a criterion of susceptibility to high-temperature brittleness for determination of the tempering modes, at which high ductility can be achieved and possibility of secondary heating cracks is eliminated: for steel P3 $-P_{\text {LM }} \geq 20.7 \cdot 10^{3}$, for steel EI415 $-P_{\text {LM }} \geq 20 \cdot 10^{3}$, and for steel P91 $-P_{\mathrm{LM}} \geq 17.6 \cdot 10^{3}$.

1. Prager, M., Sines, G. (1971) Embrittlement of precipitation hardenable nickel-base alloy by oxygen. Transact. of ASME, 93(2), 112-119.

2. Zemzin, V.N., Shron, R.Z. (1978) Heat treatment and properties of welded joints. Leningrad: Mashinostroenie.

3. Titova, T.I., Shulgan, N.A., Borovskoj, A.S. (2012) Current requirements to consumables for welding of petrochemical pressure vessels made from steel of $2.25 \mathrm{Cr}-1 \mathrm{Mo}-0.25 \mathrm{~V}$ type. In: Proc. of Sci.-Techn. Conf. on Welding Consumables, 192 201. St.-Petersburg: PI.

4. Vinkier, A.G., Pense, A.W. (1974) A review of underclad cracking in pressure-vessel components. WRC Bulletin, 197(August).
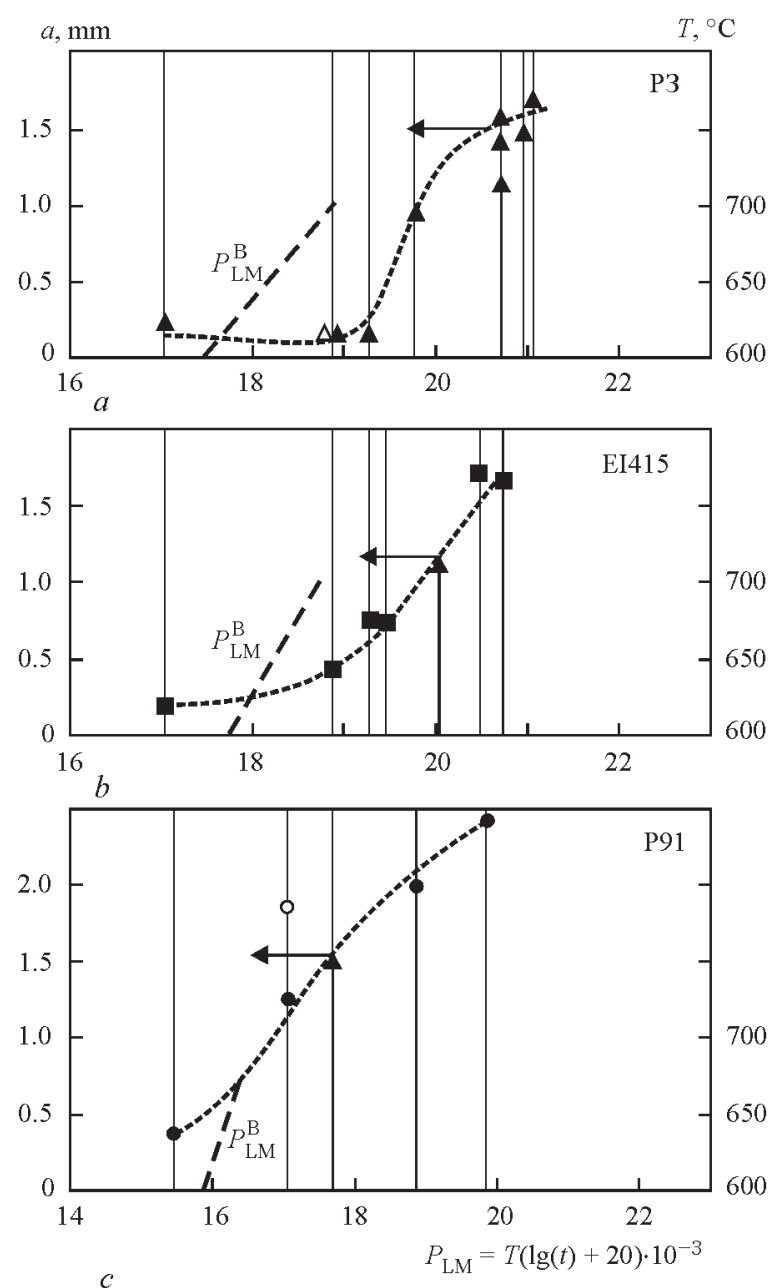

Figure 8. Effect of tempering modes on value of movement $a$ at fracture stage for steels used $(a-c)$

5. Nawrocki, J.G., DuPont, J.N., Robin, C.V. et al. (2003) The mechanism of stress-relief cracking in a ferritic alloy steel. Welding J., 82(2), 25-35.

6. Dix, A.W., Savage, W.F. (1971) Factors influencing strain-age cracking in Inconel X-750. Ibid., 50(6), 247-252.

7. Olenin, M.I., Gorynin, V.I., Timofeev, B.T. et al. (2014) Nature of thermal brittleness of steels of NPP equipment and methods of its decrease. Voprosy Materialoved., 3, 167-173.

8. Lundin, C.D., Khan, K.K. (1996) Fundamental studies of metallurgical causes and mitigation of reheat cracking in $11.4 \mathrm{Cr}-1.2 \mathrm{Mo}$ and $21.4 \mathrm{Cr}-1 \mathrm{Mo}$ steels. WRC Bulletin, 409(February).

9. Lanskaya, K.A. (1976) High-chromium heat-resistant steels. Moscow: Metallurgiya. 